\title{
Anxiolytic-Like Effect of Natural Product 2-hydroxy- 3,4,6-trimethoxyacetophenone Isolated From Croton Anisodontus in Adult Zebrafish via Serotonergic Neuromodulation Involvement of the 5-ht System
}

\section{Antonio Wlisses da Silva}

State University of Ceara: Universidade Estadual do Ceara

Maria Kueirislene A. Ferreira

State University of Ceara: Universidade Estadual do Ceara

Emanuela L. Rebouças

Federal University of Ceara: Universidade Federal do Ceara

Francisco Rogenio S. Mendes

Regional University of Cariri: Universidade Regional do Cariri

Atilano Lucas dos S. Moura

State University of Ceara: Universidade Estadual do Ceara

Marcia Machado Marinho

State University of Ceara: Universidade Estadual do Ceara

Jane Eire S. A. de Menezes

State University of Ceara: Universidade Estadual do Ceara

Emmanuel Silva Marinho

State University of Ceara: Universidade Estadual do Ceara

Hélcio S. Santos

State University of Acaraú Valley: Universidade Estadual Vale do Acarau

Alexandre Magno Rodrigues Teixeira ( $\nabla$ alexandre.teixeira@urca.br)

Regional University of Cariri: Universidade Regional do Cariri https://orcid.org/0000-0001-6786-2076

\section{Research Article}

Keywords: Croton, Anxiety, Zebrafish, 5HTR1/2C

Posted Date: March 11th, 2021

DOl: https://doi.org/10.21203/rs.3.rs-264930/v1

License: (c) (i) This work is licensed under a Creative Commons Attribution 4.0 International License.

Read Full License 
Version of Record: A version of this preprint was published at Naunyn-Schmiedeberg's Archives of Pharmacology on July 12th, 2021. See the published version at https://doi.org/10.1007/s00210-02102116-z. 


\section{Abstract}

Benzodiazepines are highly effective in combating anxiety; however, they have considerable adverse effects, so it is important to discover new safe anxiolytic agents. This study was designed to investigate the anxiolytic and anticonvulsant effect of natural product 2-hydroxy-3,4,6-trimethoxyacetophenone (HTMCX) and its possible mechanisms of action in adult zebrafish. The open field and light / dark tests ( $\mathrm{n}=6$ animals/group) were used to assess anxiety and pentylenetetrazole (PTZ) as a seizure inducer. The 96-hour acute toxicity of HTMCX was also investigated. $\operatorname{HTMCX}(1,3$, and $10 \mathrm{mg} / \mathrm{Kg} ;$ v.o.) was not toxic and affected locomotor activity. The highest doses (3 and $10 \mathrm{mg} / \mathrm{Kg} ; \mathrm{v}$.o.) produced signs of anxiolytic action in the light / dark test, and this effect was abolished by the pizotifen (antagonist 5HTR1 and 5HTR2A / 2C), having the potential to form a complex in the same region of the site indicating that the anxiolytic effect via the serotonergic mechanism. However, the anxiolytic effect of HTMCX has not been abolished by flumazenil (antagonist $\mathrm{GABAR}_{\mathrm{A}}$ ), cyproheptadine (antagonist 5HTR2A), and granisetron (antagonist 5HTR3A / 3B). Therefore, HTMCX demonstrated an anxiolytic effect, suggesting that the 5HTR1 and 5HTR / $2 \mathrm{C}$ receptors may be involved in the pharmacological performance of this acetophenone in the central nervous system.

\section{Introduction}

Neurological diseases affect millions of people worldwide (Goni et al. 2021). According to the World Health Organization (WHO), approximately 264 million people suffer from some type of anxiety disorder, and Brazil contains one of the highest rates of this pathology (Depression and other common mental disorders 2017). In the United States and Europe, anxiety has considerable social and economic costs (Ham et al. 2020). In this circumstance, it is necessary to develop research for the discovery of new drugs that have anxiolytic activity without toxicity and withdrawal effect (Sedláčková et al. 2011).

Although benzodiazepines have high effectiveness in combating anxiety, they have considerable adverse effects, which is why selective serotonin reuptake inhibitors (SSRIs) are currently the first-line drugs of choice for the treatment of anxiety disorders due to a combination of efficacy and safety. However, its effects may take time to occur. The pathological state of anxiety is associated with changes in different neurotransmission pathways, such as serotonergic, noradrenergic, GABAergic, dopaminergic, and nitrergic pathways (Martin et al. 2009; Spolidorio et al. 2007). Animal models are generally used to investigate the anxiolytic action of new compounds that act on these neuromodulation pathways.

The zebrafish (Danio rerio) has received attention as an animal model for pharmacological studies of anxiety because it has conserved neurotransmitters, and in addition, its genome has more than $80 \%$ of ortholog genes related to human diseases (Khan et al. 2017). Serotonergic neurotransmission in zebrafish has been shown to be similar to a mammal in terms of its physiology and pharmacology (Connors et al. 2014; Maximino et al. 2010; Panula et al. 2010), and studies have shown that the activation of serotonergic receptors through the use of selective agonists alters anxiety-like behaviors in zebrafish (Nowicki et al. 2014). 
Modern pharmacological research indicates that natural products derived from plants have an anxiolytic effect through neuromodulation GABAergic or serotonergic (Lei et al. 2015). Based on the reported data, this study aimed to evaluate the anxiolytic and anticonvulsant effect of 2-hydroxy-3,4,6trimethoxyacetophenone isolated from $C$. anisodontus and the possible mechanisms of action in adult zebrafish.

\section{Material And Methods}

\subsection{Drugs and reagents}

Granisetron hydrochloride (Corepharma / Inglaterra-Mx), pizotifene maleate (Central Manipulation Pharmacy / Brasil-SP), fluoxetine (Eli Lilly / EUA-IN), Cyproheptadine (Evidence Soluções Farmacêuticas / Brasil-CE), Diazepam and Pentilenotetrazol (Sigma-Aldrich / USA-MO).

\subsection{Plant material, extraction, isolation, and NMR analysis}

In this work, the 2-hydroxy-3,4,6-trimethoxyacetophenone natural product was extracted, isolated, purified, and characterized of the $C$. anisodontus (Fig. 1) (Santiago et al. 2018).

\subsection{Animals}

The fish (from 90 to 120 days; $0.4 \pm 0.1 \mathrm{~g}, 3.5 \pm 0.5 \mathrm{~cm}$ ), wild, male and female, were purchased at a local store (Fortaleza, CE) and kept for a week before the experiments in a glass aquarium $(30 \times 15 \times 20 \mathrm{~cm})$ of $10 \mathrm{~L}(\mathrm{n}=3 / \mathrm{L})$, at a temperature of $25 \pm 2{ }^{\circ} \mathrm{C}$, in light-dark cycles for $24 \mathrm{~h}$ and with chlorinated water (ProtecPlus ${ }^{\circledR}$ ) and air pump with submerged filters, at $25^{\circ} \mathrm{C}$ and $\mathrm{pH} 7.0$, under a $14: 10 \mathrm{~h}$ circadian cycle (light/dark). The animals received food (Alcon Gold Spirulina Flakes ${ }^{\circledR}$ ) ad libitum 24 hours before the experiments.

\subsection{Zebrafish}

Adult fish were randomly selected from males and females and transferred to a wet sponge; then, they were treated orally with samples of HTMCX, drugs, or controls. After treatment, the fish were transferred (individually) to beakers $(250 \mathrm{~mL})$ containing $150 \mathrm{~mL}$ of water and left to recover before testing. After the tests, the fish were sacrificed by immersion in cold water $\left(2-4^{\circ} \mathrm{C}\right)$ for 10 min until the end of the opercular movement (Matthews and Varga 2012).

All procedures were approved by the Animal Use Ethics Committee of the State University of Ceará (CEUAUECE; \# 3344801/2017).

\subsection{Toxicity to adult Zebrafish (ZFa)}

Acute toxicity was performed against the ZFa for lethal concentration $\left(\mathrm{LC}_{50}\right)$ for 96 hours in accordance with the guidelines of the Organization for Economic Cooperation and Development (OECD) (Test Guideline No. 203 - Fish, Acute Toxicity Testing 2019). After the OFT (see the section below), the fish ( $\mathrm{n}=$ 
6 / group) were transferred to tanks, separated by treatment groups, and observed for $96 \mathrm{~h}$. Dead fish in each group were counted, and the $\mathrm{LC}_{50}$ was determined.

\subsection{Assessment of locomotor capacity}

The open-field test (OFT) was carried out to identify changes in the zebrafish's motor coordination, either by sedation and/or muscle relaxation (Ahmad and Richardson 2013). The animals ( $n=6 /$ group) received $20 \mu \mathrm{L}$ of HTMCX orally at a dose of $1 \mathrm{mg} / \mathrm{kg}, 3 \mathrm{mg} / \mathrm{kg}$ or $10 \mathrm{mg} / \mathrm{kg}$. The negative control group in each experiment was treated with the vehicle (3\% DMSO; $20 \mu \mathrm{L})$, and the positive control group received Diazepam (10 mg / Kg; $20 \mu \mathrm{L} ;$ v.o.). An untreated group (Naive) was also included. After $1 \mathrm{~h}$, the fish were transferred to Petri dishes $(10 \mathrm{~cm} \times 15 \mathrm{~cm}$; with quadrants at the bottom of the plate) containing water from the tank. Locomotor activity was assessed based on the number of times that each individual crossed the lines drawn in the Petri dishes in 5 min (Gonçalves et al. 2020).

\subsection{Anxiolytic evaluation}

An animal's anxiety behavior can be observed through the light / dark test (LDT). Similar to rodents, the zebrafish naturally avoids bright areas (Gonçalves et al. 2020). The experiment was carried out in a glass aquarium $(30 \mathrm{~cm} \times 15 \mathrm{~cm} \times 20 \mathrm{~cm})$ divided into a light area and a dark area. The water tank was filled to $3 \mathrm{~cm}$ with tap water without chlorine and without drugs, which simulated a new shallow environment different from the conventional housing aquarium and capable of inducing anxiety behavior. For zebrafish ( $\mathrm{n}=6$ / group) $20 \mu \mathrm{L}$ of HTMCX were administered orally at doses of $1 \mathrm{mg} / \mathrm{kg}, 3 \mathrm{mg} / \mathrm{kg}$ or 10 $\mathrm{mg} / \mathrm{kg}$. The negative and positive control groups consisted of 3\% DMSO and $10 \mathrm{mg} / \mathrm{kg}$ Diazepam solution, respectively. An untreated group (Naive) was also included. After $1 \mathrm{~h}$, zebrafish were placed individually in the clear zone, and the anxiolytic effect was measured based on the time spent in the clear zone within 5 minutes of observation (Gebauer et al. 2011).

\subsection{Evaluation of the mechanism of action}

The receptor (s) involved in the HTMCX anxiolytic type effect was identified by pretreatment with flumazenil (GABAA antagonist) and cyproheptadine serotonergic antagonists (5-HTR2A antagonist), pizotifen (antagonist of 5-HTR1 and 5-HTR2A / 2C), and granisetron (5-HTR3A / 3B antagonist) before LDT (Benneh et al. 2017). Zebrafish ( $\mathrm{n}=6$ / group) were pretreated with flumazenil (4 mg / Kg; $20 \mu \mathrm{L} ;$ i.p.), cyproheptadine (32 mg / Kg; $20 \mu \mathrm{L} ;$ v.o.), pizotifen (32 mg / Kg; $20 \mu \mathrm{L} ;$ v.o.), or granisetron (20 mg / Kg; 20 $\mu \mathrm{L} ;$ v.o.). After $15 \mathrm{~min}$, the highest effective dose of HTMCX (10 mg/kg; $20 \mu \mathrm{L} ;$ v.o.) found in the pilot test was administered. The $3 \%$ DMSO (vehicle; $20 \mu \mathrm{L} ;$ v.o.) was used as a negative control. Diazepam (Dzp; 10 $\mathrm{mg} / \mathrm{Kg}, 20 \mu \mathrm{L} ;$ v.o.) and fluoxetine (Flx; $0.05 \mathrm{mg} / \mathrm{kg}$; i.p.) were used as $\mathrm{GABA}_{\mathrm{A}}$ and 5-HT agonists, respectively. After 1 hour of the treatments, the animals were submitted to the light / dark test described in the previous section.

\subsection{Pentylenetetrazole-induced seizure (PTZ)}

PTZ-induced seizure reversal was investigated (Siebel et al. 2015). The animals ( $\mathrm{n}=6 /$ group) were

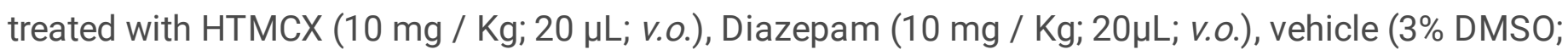


$20 \mu \mathrm{L} ;$ v.o.). An untreated group ( $\mathrm{n}=6 /$ group) was included (Naive).

After $1 \mathrm{~h}$, the animals were exposed to PTZ $(7.5 \mathrm{mM})$, and the behavior similar to seizure in three stages was evaluated: stage I - dramatically increased swimming activity; stage II - swirling swimming behavior; stage III - clonus-like seizures, followed by loss of posture when the animal falls to one side and remains immobile for 1-3 s. At the end of the evaluation of the three stages of the test, the animals were euthanized on the ice.

\subsection{Docking procedure}

The structure of the human 5-HT1B receptor (PDB 4IAQ) was obtained from the Protein Data Bank (https://www.rcsb.org/), identified as "Crystal structure of the chimeric protein of 5-HT1B-BRIL in complex with dihydroergotamine (PSI Community Target) ", deposited with a resolution of $2.80 \AA$, being determined by X-Ray diffraction, classified as signaling protein and electron transport, Homo sapiens organisms, Escherichia coli and Spodoptera frugipera expression system (Wang et al. 2013). Molecular docking simulations were performed using the Auto Dock Vina code (version 1.1.2) (Trott and Olson 2010). The grid box was defined by centralizing the entire protein, with parameters of $70 \AA ̊ x 100 \AA x 76 \AA$ and dimensions $(x, y, z)=(-21,133,-0,855,17,314)$, with 50 independent simulations with 20 poses each. The Discovery Studio Visualizer (Biovia 2017) and UCSF Chimera (Pettersen et al. 2004) codes were used to analyzing the results.

\subsection{Statistical analysis}

The results were expressed as mean \pm standard deviation from the mean for in vivo tests ( $n=6 /$ group). After confirming the normality and homogeneity distribution of the data, differences between the groups were subjected to analysis of variance (one-way ANOVA), followed by the Tukey test, using the GraphPad Prism v software. 7.0. The level of statistical significance was considered to be $5 \%(p<0.05)$.

\section{Results}

\subsection{Acute toxicity $(96 \mathrm{~h})$}

The natural product HTMCX was non-toxic to adult zebrafish up to $96 \mathrm{~h}$ of analysis $\left(\mathrm{LC}_{50} \otimes 10 \mathrm{mg} / \mathrm{kg}\right.$ ), as there was no death and did not cause any apparent anatomical changes in the animals during this period.

\subsection{Open field test (OFT)}

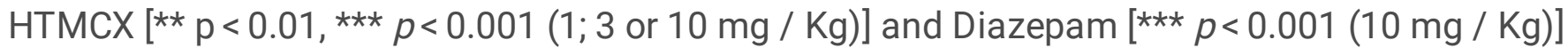
significantly decreased the locomotor activity of the adult zebrafish compared to control groups (Naive and vehicle) (Fig. 2A).

\subsection{Anxiolytic evaluation (LDT)}




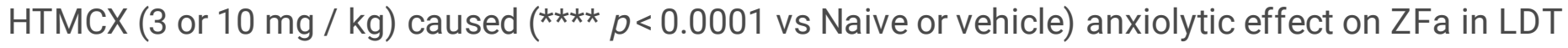
(Fig. 2B). This effect was significantly similar to the effect of Diazepam (Dzp; $10 \mathrm{mg} / \mathrm{Kg} ;$ v.o.), positive control. Only the lowest dose of HTMCX $(1 \mathrm{mg} / \mathrm{kg})$ did not have an anxiolytic effect.

\subsection{Involvement of the GABAergic system (GABA)}

Flumazenil did not reduce the anxiolytic effect of acetophenone HTMCX (10 mg / Kg, v.o.), and reduced (\# \#p<0.01 vs. Dzp) the anxiolytic effect of Diazepam (Dzp; $10 \mathrm{mg} / \mathrm{Kg} ;$ v.o.) (Fig. 2C).

\subsection{Involvement of the serotonergic system (5-HT)}

\subsubsection{System involvement 5-HTR $2 \mathrm{~A}$}

Cyproheptadine did not reverse the anxiolytic effect of HTMCX (10 mg / Kg, v.o.), however, it reduced (\# \# $\# \# p<0.0001$ vs. Flx) the anxiolytic effect of fluoxetine (Flx; $0.05 \mathrm{mg} / \mathrm{Kg} ;$ i.p.) (Fig. 2D).

\subsubsection{Involvement of 5-HTR and $5-\mathrm{HTR}_{2 \mathrm{~A} / 2 \mathrm{C}}$ systems}

Pizotifen reduced (\# \# \# \#p 0.0001 vs. HTMCX or Flx) the anxiolytic effect of HTMCX (10 mg / Kg, v.o.) and fluoxetine (Flx; $0.05 \mathrm{mg} / \mathrm{Kg} ;$ i.p.), indicating that HTMCX has an anxiolytic effect through neuromodulation of the $5-\mathrm{HTR}_{1}$ and $5-\mathrm{HTR}_{2 \mathrm{C}}$ channels (Fig. 2E).

\subsubsection{Involvement of 5-HTR $3 \mathrm{~A} / 3 \mathrm{~B}$ systems}

Granisetron did not reverse the anxiolytic effect of (10 mg / Kg, v.o.), however, it reduced (\# \#\#\#p< 0.0001 vs. Flx) the anxiolytic effect of fluoxetine (Flx; $0.05 \mathrm{mg} / \mathrm{Kg} ;$ i.p.) (Fig. 2F).

\subsection{Pentylenetetrazole-induced seizures (PTZ)}

HTMCX (10 mg / Kg; v.o.) did not reverse the convulsive behavior induced by PTZ, unlike [ $(\star \star ~ p<0.01$, Stage I; ${ }^{\star \star \star} p<0.001$, stage II; $* \star p<0.01$, stage III )] of Dzp (10 mg / Kg; v.o.) that delayed the onset of the three stages of the seizure in the aZF compared to the control groups (Naive and vehicle) $[(\star \star \star ~ p<0.001$, Stage I and stage II; $* \star p<0.01$, stage III)] (Fig. 3).

\subsection{Docking of the anxiolytic effect}

The best conformation simulation between HTMCX and the receptor coupled to the human G 5-HT1B protein presented a RMSD (Root Mean Square Deviation) value in the order of 1,452 and an affinity energy value in the order of $-6.0 \mathrm{kcal} \mathrm{mol}^{-1}$. The trimethoxyacetophenone-5-HT1B complex formed showed four interactions, two hydrophobic with residues ILE130A, VAL201A, and two hydrogen bonds of strong intensity with residues THR134A and ASP129A (Table 1). 
Table 1

Interactions between the $5-\mathrm{HT} 1 \mathrm{~B}$ receptor and the HTMCX ligand.

\begin{tabular}{|llll|}
\hline Ligand & Receptor & Interaction & Distance $(\AA)$ \\
\hline HTMCX & ILE130A* & Hydrophobic & $3.89 \AA$ \\
\cline { 2 - 4 } & VAL201A* & Hydrophobic & $3.86 \AA$ \\
\cline { 2 - 4 } & ASP129A & H-Bond & $2.77 \AA$ \\
\cline { 2 - 4 } & THR134A* & H-Bond & $2.51 \AA$ \\
\hline * 2GM orthostatic site residue. & \\
\hline
\end{tabular}

\section{Discussion}

The OFT was initially performed to evaluate the effect of 2-hydroxy-3,4,6-trimethoxyacetophenone (HTMCX) on the locomotion of adult zebrafish. This test allows an evaluation of the stimulating or depressing activity of compounds and can also indicate more specific behaviors, such as anxiety. Thus, it was observed that HTMCX caused locomotor impairment (Fig. 2A) a result similar to those obtained with anxiolytic drugs that caused a sedative effect and decreased locomotor activity in animals (Gupta et al. 2014). In addition, HTMCX was non-toxic during the $96 \mathrm{~h}$ of analysis.

Zebrafish are anxious under natural conditions, preferring dark environments. Moreover, new environments are potentially risky and trigger anxiety in them. The preference of these animals for the clear region of the aquarium is characterized by the action of anxiolytic substances in the central nervous system (CNS) (Maximino et al. 2011). LDT was performed to confirm the possible effect of the HTMCX anxiolytic type observed in OFT. The higher doses of acetophenone HTMCX and Diazepam significantly increased the time of the animals in the clear region of the aquarium (Fig. 2B), allowing the assumption that this natural product has an acute anxiolytic effect, confirming the results observed in the OFT.

LDT and OFT showed that HTMCX and Diazepam have similar effects on zebrafish. Benzodiazepines have a depressant/sedative effect on the CNS of zebrafish and mammals through positive allosteric neuromodulation of the $\mathrm{GABA}_{\mathrm{A}}$ receptor, which causes hypnotic effects, locomotor deficiency, and anxiolytic effects (Griffin et al. 2013). Flumazenil is a GABAergic receptor antagonist well known for antagonizing the sedative / hypnotic effects caused by benzodiazepine overdoses. It reverses these effects by binding to the $a[1-3,5] \beta y$ subunits of these receptors (Penninga et al. 2016). Pretreatment with flumazenil did not alter the effects of HTMCX on zebrafish (Fig. 2C). However, flumazenil sharply reduced the anxiolytic effect in fish treated with Diazepam. However, the anxiolytic activity of HTMCX is independent of the GABAergic system.

Pentylenetetrazole is also an antagonist of GABAergic receptors; however, it is used in zebrafish to induce epileptic-like effects and to study seizures (Shaikh et al. 2013). The anticonvulsant effect of HTMCX and 
Dzp on PTZ-induced seizures in adult zebrafish was evaluated. However, HTMCX did not increase the latency time for the onset of seizures (Fig. 3). Unlike Dzp, which increased the latency time for the onset of crises in the three stages. These results corroborate data obtained from the mechanism of action of the $\mathrm{GABA}_{\mathrm{A}}$ receptor with flumazenil (Fig. $2 \mathrm{C}$ ), demonstrating that there is no action of HTMCX in the GABAergic system.

Serotonergic neuromodulation is also involved in the mechanisms of anxiety mediation, and the role of serotonin (5-HT) in this disorder is widely investigated (Maximino et al. 2014). Anxiety behavior in LDT is positively associated with extracellular levels of 5-HT in the zebrafish brain (Gonçalves et al. 2020). Thus, high levels of 5-HT can cause effects similar to those of anxiety, while low levels generally cause anxiolytic behaviors (Nowicki et al. 2014).

Considering the hypothesis that serotonergic neurotransmission mediates anxiolytic effects, the participation of this system in the anxiolytic action of HTMCX after pretreatment with cyproheptadine antagonists (a 5- $\mathrm{HTR}_{2 \mathrm{~A}}$ antagonist), pizotifen (a 5-HTR 1 and 5- $\mathrm{HTR}_{2 \mathrm{~A} / 2 \mathrm{C}}$ antagonist), and granisetron (a 5-HTR $\mathrm{H}_{3}$ antagonist) was evaluated. Fluoxetine was used as a positive control. Unlike granisetron (5$\mathrm{HTR}_{3 \mathrm{~A} / 3 \mathrm{~B}}$; Fig. 2E) and cyproheptadine (5- $\mathrm{HT}_{2 \mathrm{~A}}$; Fig. 2D), pretreatment with pizotifen significantly inhibited the acute anxiolytic effect of HTMCX, suggesting that the mechanism of action of this acetophenone involves the $5-\mathrm{HTR}_{1}$ and/or $5 \mathrm{HT}_{2 \mathrm{C}}$ serotonergic receptors (Fig. 2D). However, it does not involve the $5 \mathrm{HT}_{2 \mathrm{~A}}$ receptor because cyproheptadine did not reverse the anxiolytic effect of $\mathrm{HTMCX}$ on LDT. In addition, it was observed that all the mentioned antagonists reversed the effects of fluoxetine (Fig. 2C, D, and F).

5HT1A receptor agonist substances exhibit antidepressant and/or anxiolytic effects. 5-HTR $\mathrm{H}_{1}$ is an inhibitory receptor coupled to protein $\mathrm{G}$, and its activation reduces the rate of firing of serotonergic neurons, promotes the synthesis, renewal, and release of 5-HT in various areas of the CNS (Gonçalves et al. 2020). Studies have shown that zebrafish treated with $5 \mathrm{HT}_{1 \mathrm{~A}}$ receptor agonists showed anxiolytic behaviors (Benneh et al. 2017; Gonçalves et al. 2020; Maximino et al. 2014). Therefore, HTMCX is possibly a 5-HTR 1 A agonist, as it prevented the animals' anxiolytic effect (Fig. 2E).

The serotonin $2 \mathrm{C}$ receptor $\left(5-\mathrm{HTR}_{2 \mathrm{C}}\right)$ is a molecular target of drugs developed for the treatment of behavioral conditions, such as eating and mood disorders, anxiety, and motor behavior (Lee et al. 2010). The genetic similarities of mammalian $5-\mathrm{HTR}_{2 \mathrm{C}}$ with that of zebrafish indicate the use of this model to study the role of the $5-\mathrm{HT}_{2 \mathrm{C}}$ receptor in the behavior, development, and discovery of drugs that act in this channel. Reports indicate that $5-\mathrm{HTR}_{2 \mathrm{C}}$ activation induces panic and/or anxiety while blocking it causes anxiolytic effect (Chagraoui et al. 2016). Thus, HTMCX may have competed with pizotifen and was replaced by it in $5-\mathrm{HTR}_{2}$, being indicative of the action of this acetophenone in the anxiolytic effect under this route. 
For the study of the anxiolytic effect in silico, via serotonergic neuromodulation of HTMCX, the structure of the receptor coupled to the human G 5-HT1B protein was selected due to its orthostatic site composed of residues conserved in practically the entire family of the receptor 5-HT (Morgan et al. 2013). The dihydroergotamine agonist (2GM) is complexed in the protein at the orthostatic site, composed of residues ILE130, CYS133, THR134, VAL201, ALA216, PHE331, ASP352, and THR355. After the molecular docking simulations, it was possible to observe that the HTMCX coupled in the same region of the orthostatic site (Fig. 4), showing four interactions that vary between $2.51 \AA$ and $3.89 \AA$ in distance, with three interactions with the residues of the dihydroergotamine site ILE130A, VAL201A, THR134A (two hydrophobic interactions and a hydrogen bond of strong intensity) and a hydrogen bond with the ASP129A residue (Table 1).

\section{Conclusion}

The results of this study show that acetophenone HTMCX was non-toxic and demonstrated an anxiolytic effect in adult zebrafish. Acetophenone HTMCX exhibited an anxiolytic effect through the 5-HT 1 and 5$\mathrm{HT}_{2 \mathrm{C}}$ systems, having the potential to form a complex in the same region of the orthosteric site, indicating that the anxiolytic effect via the serotonergic mechanism. Our results confirm the pharmacological relevance of HTMCX as an anxiety inhibitor, enabling new therapeutic approaches to be investigated.

\section{Declarations}

Funding This research was funded by Fundação Cearense de Apoio ao Desenvolvimento Científico e Tecnológico - FUNCAP (Grant number BP4-0172-00075.01.00/20 for Hélcio Silva dos Santos), and Coordenação de Aperfeiçoamento de Pessoal de Nível Superior (CAPES) (Finance code 001 for Antonio Wlisses da Silva).

Conflicts of interest/Competing interests The authors declare no conflicts of interest. The authors also declare that they have no known competing financial interests or personal relationships that could have appeared to influence the work reported in this paper.

Availability of data and material The analyzed data sets generated during the study are available from the corresponding author on request.

Code availability The authors thank Centro Nacional de Processamento de Alto Desempenho (CENAPAD) of the Federal University of Ceará (UFC) for the use of the AutoDock Vina software. The Discovery Studio Visualizer and UCSF Chimera free software were used to analyzing the results of the research.

Authors' contributions Antonio Wlisses da Silva: Investigation, Formal analysis, Writing-review and editing; Maria Kueirislene A. Ferreira: Methodology; Emanuela L. Rebouças: Visualization; Francisco Rogenio S. Mendes: Methodology; Atilano Lucas dos S. Moura: Data curation; Marcia Machado Marinho: Software, Visualization; Jane Eire S. A. de Menezes: Conceptualization; Emmanuel Silva Marinho: 
Software, Writing-review and editing; Hélcio S. Santos: Project administration, Writing-review and editing. Alexandre Magno Rodrigues Teixeira: Supervision, Writing-review, and editing.

\section{Compliance with ethical standards}

Ethics approval All procedures performed in studies involving zebrafish-based animal were approved by the Animal Use Ethics Committee of the State University of Ceará (CEUA-UECE; \# 3344801/2017). All methods were performed in accordance with the relevant guidelines and regulations.

Consent to participate Informed consent forms were obtained from all study participants.

Consent for publication Not applicable.

\section{References}

Ahmad F, Richardson MK (2013) Exploratory behaviour in the open field test adapted for larval zebrafish: Impact of environmental complexity. Behav Processes 92:88-98.

https://doi.org/10.1016/j.beproc.2012.10.014

Benneh CK, Biney RP, Mante PK, Tandoh A, Adongo DW, Woode E (2017) Maerua angolensis stem bark extract reverses anxiety and related behaviours in zebrafish-Involvement of GABAergic and 5-HT systems. J Ethnopharmacol 207:129-145. https://doi.org/10.1016/j.jep.2017.06.012

Biovia DS (2017) Discovery Studio Visualizer. Dassault Systemes, BIOVIA Corp., San Diego, CA, USA Chagraoui A, Thibaut F, Skiba M, Thuillez C, Bourin M (2016) 5-HT2C receptors in psychiatric disorders: A review. Prog Neuro-Psychopharmacol Biol Psychiatry 66:120-135.

https://doi.org/10.1016/j.pnpbp.2015.12.006

Connors KA, Valenti TW, Lawless K, Sackerman J, Onaivi ES, Brooks BW, Gould GG (2014) Similar anxiolytic effects of agonists targeting serotonin 5-HT1A or cannabinoid CB receptors on zebrafish behavior in novel environments. Aquat Toxicol 151:105-113.

https://doi.org/10.1016/j.aquatox.2013.12.005

Depression and other common mental disorders (2017). World Health Organization

Gebauer DL, Pagnussat N, Piato ÂL, Schaefer IC, Bonan CD, Lara DR (2011) Effects of anxiolytics in zebrafish: Similarities and differences between benzodiazepines, buspirone and ethanol. Pharmacol Biochem Behav 99:480-486. https://doi.org/10.1016/j.pbb.2011.04.021

Gonçalves NGG, de Araújo JIF, Magalhães FEA, Mendes FRS, Lobo MDP, Moreira ACdOM, Moreira RdA (2020) Protein fraction from Artocarpus altilis pulp exhibits antioxidant properties and reverses anxiety behavior in adult zebrafish via the serotoninergic system. J Funct Foods 66:103772.

https://doi.org/10.1016/j.jff.2019.103772

Page $11 / 16$ 
Goni 0 et al. (2021) Pharmacological insights on the antidepressant, anxiolytic and aphrodisiac potentials of Aglaonema hookerianum Schott. J Ethnopharmacol 268:113664.

https://doi.org/10.1016/j.jep.2020.113664

Griffin CE, 3rd, Kaye AM, Bueno FR, Kaye AD (2013) Benzodiazepine pharmacology and central nervous system-mediated effects. Ochsner J 13:214-223

Gupta P, Khobragade S, Rajaram S, Shingatgeri V (2014) Assessment of locomotion behavior in adult Zebrafish after acute exposure to different pharmacological reference compounds. Drug Des Devel Ther 5 Ham HJ, Lee YS, Yun J, Han S-B, Son DJ, Hong JT (2020) Anxiolytic-like effects of the ethanol extract of Magnolia obovata leaves through its effects on GABA-benzodiazepine receptor and neuroinflammation. Behav Brain Res 383:112518. https://doi.org/10.1016/j.bbr.2020.112518

Khan KM et al. (2017) Zebrafish models in neuropsychopharmacology and CNS drug discovery. $\mathrm{Br} \mathrm{J}$ Pharmacol 174:1925-1944. https://doi.org/10.1111/bph.13754

Lee J, Jung ME, Lee J (2010) 5-HT2C receptor modulators: a patent survey. Expert Opin Ther Pat 20:14291455. http://dx.doi.org/10.1517/13543776.2010.518956

Lei L, Changhong L, Yicun W, Pu W, Yuxin L, Bingjin L (2015) Herbal Medicine for Anxiety, Depression and Insomnia. Curr Neuropharmacol 13:481-493. http://dx.doi.org/10.2174/1570159X1304150831122734

Martin El, Ressler KJ, Binder E, Nemeroff CB (2009) The Neurobiology of Anxiety Disorders: Brain Imaging, Genetics, and Psychoneuroendocrinology. Psychiatr Clin North Am 32:549-575. https://doi.org/10.1016/j.psc.2009.05.004

Matthews M, Varga ZM (2012) Anesthesia and Euthanasia in Zebrafish. ILAR Journal 53:192-204. http://dx.doi.org/10.1093/ilar.53.2.192

Maximino C, da Silva AWB, Gouveia A, Herculano AM (2011) Pharmacological analysis of zebrafish (Danio rerio) scototaxis. Prog Neuro-Psychopharmacol Biol Psychiatry 35:624-631. https://doi.org/10.1016/j.pnpbp.2011.01.006

Maximino C, de Brito TM, da Silva Batista AW, Herculano AM, Morato S, Gouveia A (2010) Measuring anxiety in zebrafish: A critical review. Behav Brain Res 214:157-171.

https://doi.org/10.1016/j.bbr.2010.05.031

Maximino C, Lima MG, Costa CC, Guedes IML, Herculano AM (2014) Fluoxetine and WAY 100,635 dissociate increases in scototaxis and analgesia induced by conspecific alarm substance in zebrafish (Danio rerio Hamilton 1822). Pharmacol Biochem Behav 124:425-433. https://doi.org/10.1016/j.pbb.2014.07.003 
Morgan GA, Campbell BA, Carter LM, Plaut JJ, Phillips RJ (2013) 3D Reconstruction of the Source and Scale of Buried Young Flood Channels on Mars. Science 340:607.

http://dx.doi.org/10.1126/science.1234787

Nowicki M, Tran S, Muraleetharan A, Markovic S, Gerlai R (2014) Serotonin antagonists induce anxiolytic and anxiogenic-like behavior in zebrafish in a receptor-subtype dependent manner. Pharmacol Biochem Behav 126:170-180. https://doi.org/10.1016/j.pbb.2014.09.022

Panula P, Chen YC, Priyadarshini M, Kudo H, Semenova S, Sundvik M, Sallinen V (2010) The comparative neuroanatomy and neurochemistry of zebrafish CNS systems of relevance to human neuropsychiatric diseases. Neurobiol Dis 40:46-57. https://doi.org/10.1016/j.nbd.2010.05.010

Penninga El, Graudal N, Ladekarl MB, Jürgens G (2016) Adverse Events Associated with Flumazenil Treatment for the Management of Suspected Benzodiazepine Intoxication - A Systematic Review with Meta-Analyses of Randomised Trials. Basic Clin Pharmacol Toxicol 118:37-44.

https://doi.org/10.1111/bcpt.12434

Pettersen EF, Goddard TD, Huang CC, Couch GS, Greenblatt DM, Meng EC, Ferrin TE (2004) UCSF Chimera -A visualization system for exploratory research and analysis. J Comput Chem 25:1605-1612.

https://doi.org/10.1002/jcc.20084

Santiago RNS et al. (2018) Crystal structure, vibrational spectra and quantum chemical parameters of 2hydroxy-3,4,6-trimethoxyacetophenone isolated from the Croton anisodontus Müll. Arg. (Euphorbiaceae). J Mol Struct 1171:815-826. https://doi.org/10.1016/j.molstruc.2018.06.064

Sedláčková N, Ponechalová V, Ujházy E, Dubovický M, Mach M (2011) Anxiolytic activity of pyridoindole derivatives SMe1EC2 and SMe1M2: behavioral analysis using rat model. Interdiscip Toxicol 4:211-215. https://doi.org/10.2478/v10102-011-0032-8

Shaikh MF, Sancheti J, Sathaye S (2013) Effect of Eclipta alba on Acute Seizure Models: a GABA(A)mediated Effect. Indian J Pharm Sci 75:380-384. http://dx.doi.org/10.4103/0250-474x.117432

Siebel AM et al. (2015) Role of Adenosine Signaling on Pentylenetetrazole-Induced Seizures in Zebrafish. Zebrafish 12:127-136. http://dx.doi.org/10.1089/zeb.2014.1004

Spolidorio PCM, Echeverry MB, lyomasa M, Guimaraes FS, Del Bel EA (2007) Anxiolytic effects induced by inhibition of the nitric oxide-cGMP pathway in the rat dorsal hippocampus. Psychopharmacology 195:183-192. http://dx.doi.org/10.1007/s00213-007-0890-0

Test Guideline No. 203 - Fish, Acute Toxicity Testing (2019). OECD

Trott O, Olson AJ (2010) Software News and Update AutoDock Vina: Improving the Speed and Accuracy of Docking with a New Scoring Function, Efficient Optimization, and Multithreading. J Comput Chem 31:455-461. http://dx.doi.org/10.1002/jcc.21334

Page 13/16 
Wang C et al. (2013) Structural Basis for Molecular Recognition at Serotonin Receptors. Science 340:610. http://dx.doi.org/10.1126/science.1232807

\section{Figures}
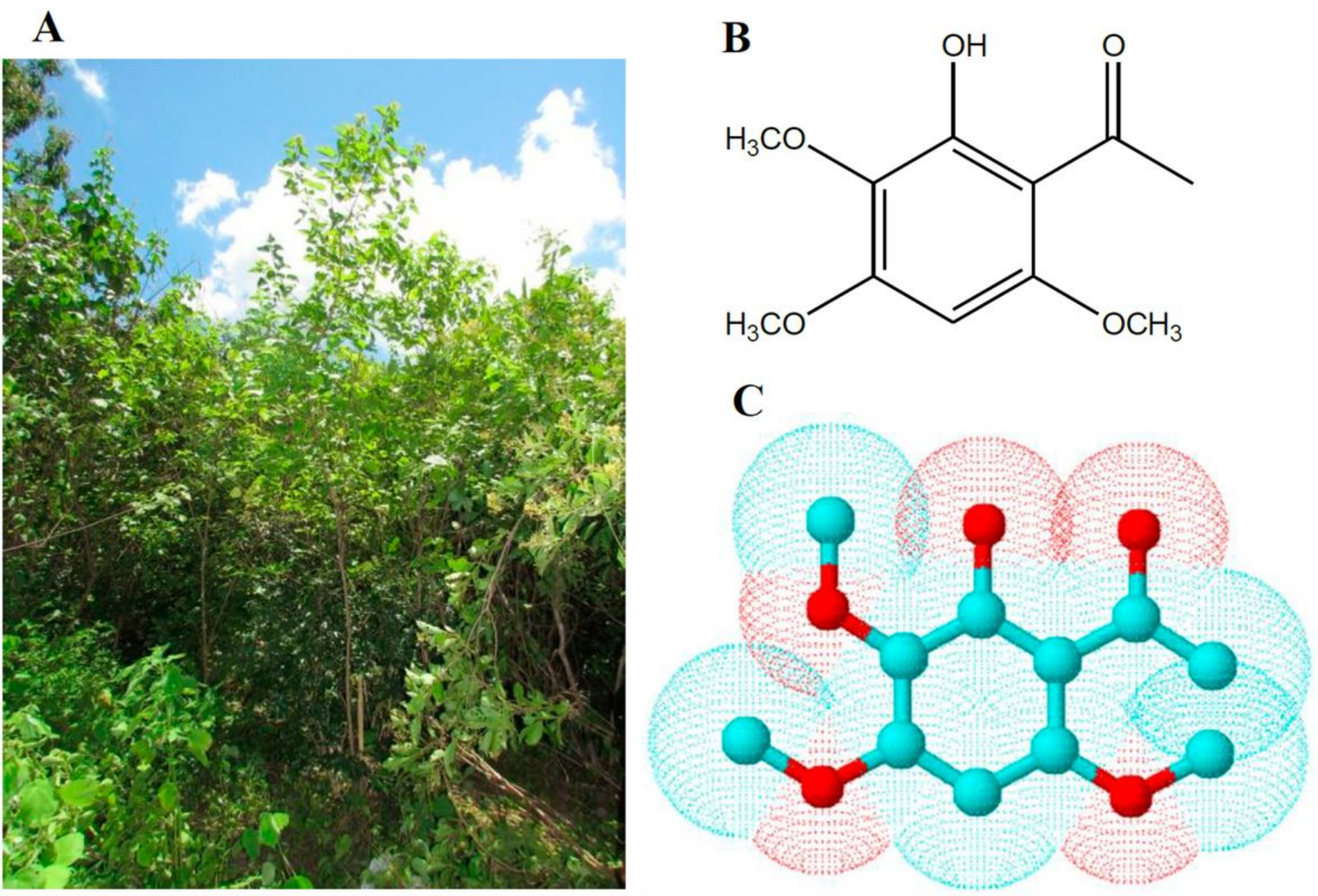

Figure 1

Croton anisodontus (A), structural representation (B) and three-dimensional structure (C) of the 2-hydroxy3,4,6-trimethoxyacetophenone (HTMCX) 
A
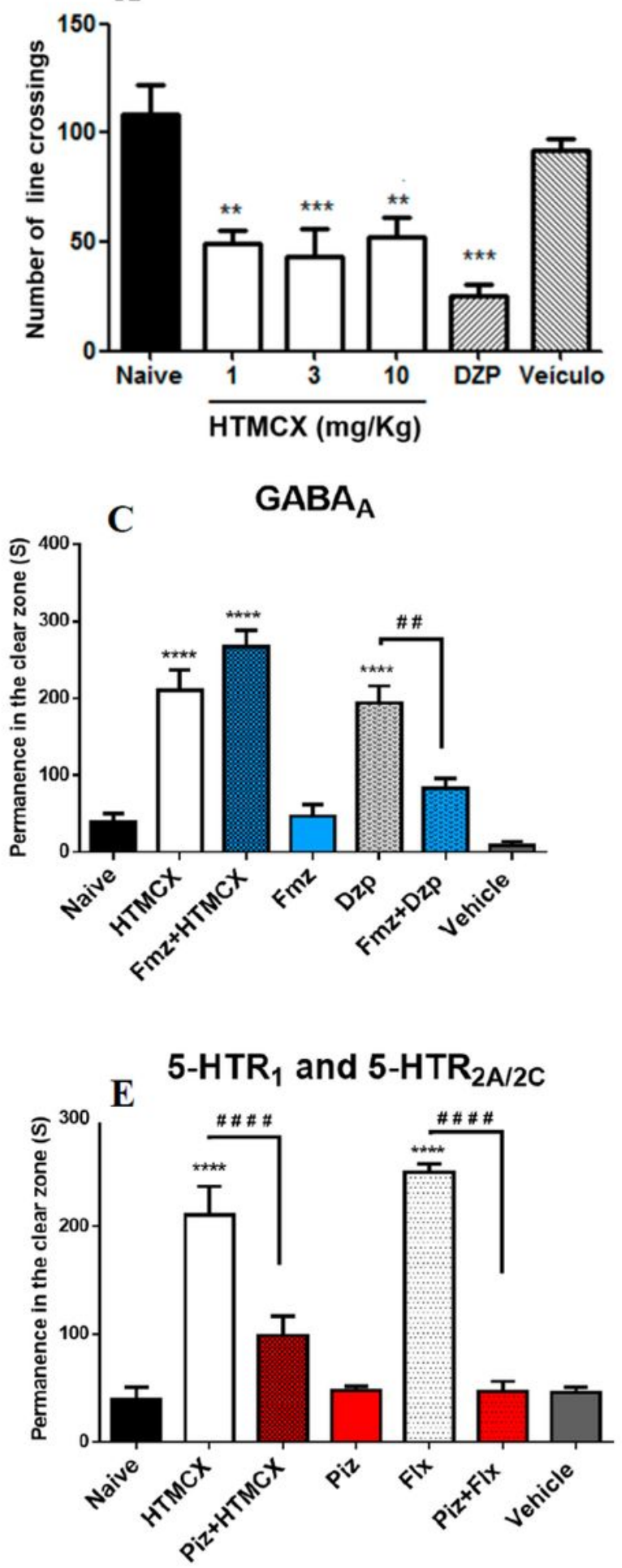

B
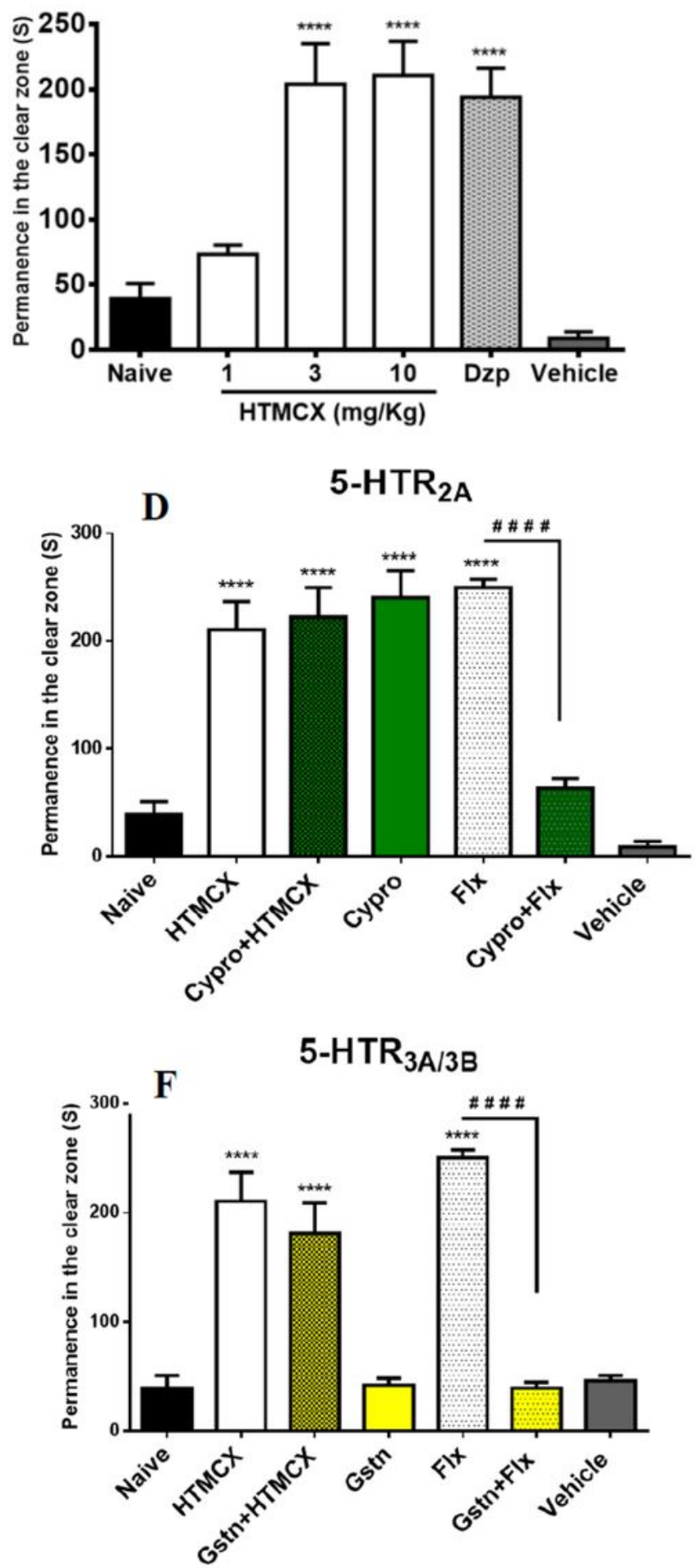

Figure 2

Effect under the locomotor behavior of zebrafish (Danio rerio) adult in the Open Field Test (A) and anxiolytic-like effect in the Light \& Dark Test (B) of the HTMCX (20 $\mu \mathrm{L}$; v.o.). Anxiolytic-like effect of HTMCX after pretreatment with flumazenil (C), cyproheptadine (D), pizotifen (E), and granisetron (F) in adult zebrafish in the light/dark test (0-5 min). Naive-untreated animals. Dzp - Diazepam (10 mg/Kg; 20 $\mu \mathrm{L} ;$ v.o.). Vehicle (DMSO 3\%) (20 $\mu \mathrm{L}$; v.o.). The results are expressed as mean values $\pm \mathrm{S} E \mathrm{M}$. ( $\mathrm{n}=$ 


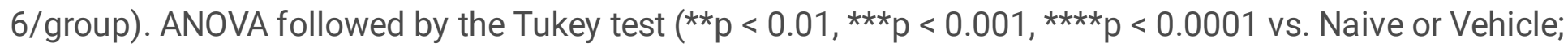
\#\#p < 0.01, \#\#\#\# < 0.0001 vs. HTMCX or Flx or Dzp). Dzp - Diazepam, Cipro - cyproheptadine; Gstn granisetron; Piz - pizotifene; Flx - fluoxetine.
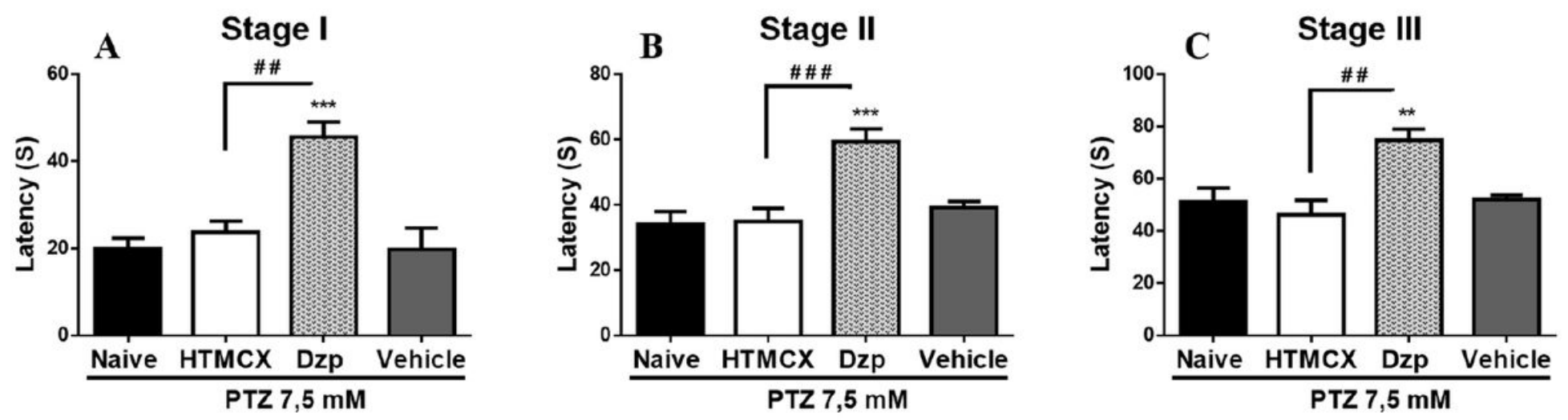

Figure 3

Effect of HTMCX on pentylenetetrazole-induced seizure in adult zebrafish, Stage I (A), Stage II (B), Stage III (C). Dzp - Diazepam (10 mg/Kg; $20 \mu \mathrm{L}$, v.o.); Vehicle - 3\% DMSO (20 $\mu \mathrm{L}$; v.o.). The values represent the mean \pm standard error of the mean (E.P.M.) for 6 animals/group. ANOVA followed by Tukey $(* \star p<0.01$, *** $p<0.001$ vs. Naïve or Vehicle; \# \# p <0,01; \# \# \# $<0.001$ vs. Dzp).
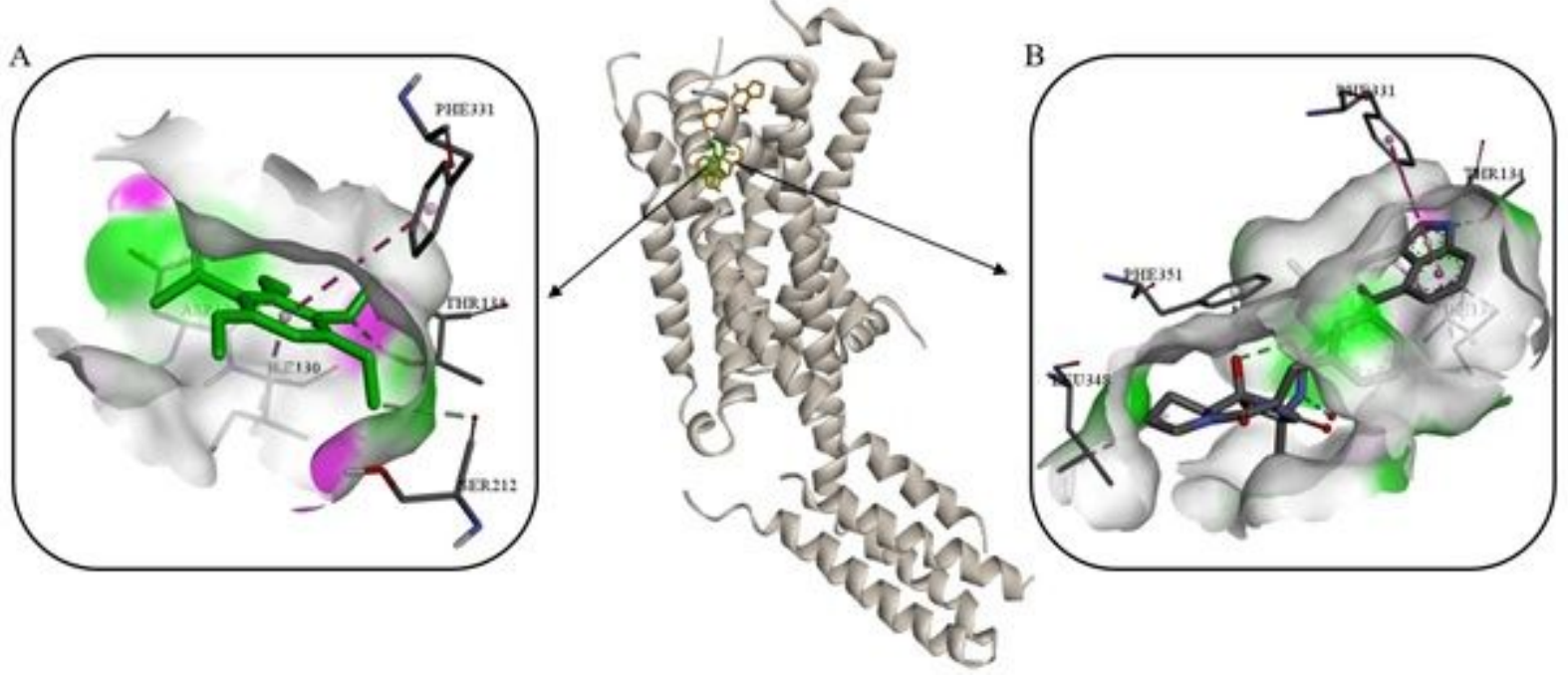

Figure 4

5-HT1B receptor interaction complex with acetophenone $(A)$ and the co-crystallized inhibitor Dihydroergotamine (B). 